\title{
Eu mudo, nós mudamos? Perspectivas sobre o trabalho dos Agentes Comunitários de Saúde
}

\author{
I change, do we change? Perspectives on the work of Community Health \\ Agents
}

¿Yo cambio, nos cambiamos? Perspectivas sobre el trabajo de los Agentes de Salud Comunitarios

Tiago Pereira de Souza ${ }^{1}$, Paulo Antonio Barros Oliveira ${ }^{2}$

\footnotetext{
${ }^{1}$ Programa de Pós-Graduação em Educação em Ciências "Química da Vida e Saúde", da Universidade Federal do Rio Grande do Sul. Porto Alegre - Rio Grande do Sul

${ }^{2}$ Departamento de Medicina Social da Universidade Federal do Rio Grande do Sul. Porto Alegre -

Rio Grande do Sul
}

\section{RESUMO}

Este artigo visa analisar o processo de trabalho e as perspectivas de mudanças, a fim de proporcionar reflexões sobre a prática cotidiana de 62 Agentes Comunitários de Saúde da cidade de Campo Bom, no Rio Grande do Sul, Brasil. Os dados obtidos foram coletados através de entrevistas individuais e questionários autopreenchidos, e a análise dos conteúdos foi feita a partir da construção do Discurso do Sujeito Coletivo. A maioria dos trabalhadores relata que haveria algo a ser modificado no seu processo de trabalho. Dentre os aspectos a serem modificados e/ou melhorados estão: burocratização do trabalho, reorganização das marcações de consulta, respeito, união das equipes, maior participação dos profissionais de saúde (médicos

Autor de Correspondência:

*Tiago Pereira de Souza. E-mail: tiago.ps.fono@gmail.com 
e enfermeiros) nas visitas domiciliares, equipes incompletas, automatização do processo de trabalho, grande número de famílias cadastradas, reconhecimento, ausência e/ou sucateamento de materiais básicos de trabalho.

Palavras-chave: Atenção Primária à Saúde. Saúde da Família. Saúde do Trabalhador. Agentes Comunitários de Saúde.

\begin{abstract}
This article aims to analyze the work process and the perspectives of changes, in order to provide reflections about the daily practice of 62 Community Health Agents in the city of Campo Bom, in Rio Grande do Sul, Brazil. Data obtained were collected using individual interviews and self-administered questionnaires and content analysis was made from the construction of the Collective Subject Discourse. Most workers report that there would be something to change in their work process. Among the aspects to be modified and / or improved are: bureaucratization of work, reorganization of appointments, respect, unity of teams, greater participation of health professionals (doctors and nurses) in home visits, incomplete teams, automation of the work process, large number of registered families, recognition, absence and / or deterioration of basic work materials.
\end{abstract}

Keywords: Primary Health Care. Family Health. Occupational Health. Community Health Workers.

\title{
RESUMEN
}

Este artículo tiene como objetivo analizar el proceso de trabajo y las perspectivas de los cambios, a fin de proporcionar reflexiones sobre la práctica diaria de 62 agentes comunitarios de salud en la ciudad de Campo Bom, en Rio Grande do Sul, Brasil. Los datos obtenidos se recolectaron a través de entrevistas individuales y cuestionarios autoadministrados y el análisis de contenido se realizó a partir de la construcción del Discurso del sujeto colectivo. La mayoría de los trabajadores informan que habría algo que cambiar en su proceso de trabajo. Entre los aspectos a cambiar y / o mejorar se encuentran: burocratización del trabajo, reorganización de citas, respeto, unidad de equipos, mayor participación de profesionales de la salud (médicos y enfermeras) en visitas domiciliarias, equipos incompletos, automatización del proceso de trabajo, gran número de familias registradas, reconocimiento, ausencia y / o desguace de materiales básicos de trabajo.

Palabras clave: Atención Primaria de Salud. Salud de la Familia. Salud Laboral. Agentes Comunitarios de Salud. 


\section{INTRODUÇÃO}

O papel de mediação consolida a principal característica do trabalho dos Agentes Comunitários de Saúde (ACSs), visto que são trabalhadores com experiências cotidianas capazes de oferecer contrapontos importantes no cuidado dos usuários. São articuladores em potencial das ações em saúde e oferecem para as equipes um "olhar" diferenciado da lógica cartesiana e mecanicista tradicionalmente atribuída à atual configuração da formação em saúde. Por estarem inseridos e vivenciarem dia após dia as movimentações comunitárias, possuem um entendimento ampliado da forma como se organizam as relações sociais, culturais, econômicas e ambientais do campo de trabalho da atenção primária ${ }^{1}$.

Legalmente reconhecidos pela Lei n. 11.350, de 5 de outubro de 2006, os sujeitos aqui estudados representam uma mudança no modo de cuidado estabelecido na atenção primária, estabelecendo correlações entre usuários e comunidade adstrita $^{2}$. Exercem representação mútua enquanto trabalhadores e moradores das áreas de cobertura da Estratégia de Saúde da Família (ESF), caracterizando uma política de emancipação e rompimento do modelo biomédico centrado na doença, uma vez que propõem um processo de trabalho com objetivos claros voltados à promoção da saúde e à prevenção de doenças.

As diretrizes ministeriais que orientam o trabalho do ACS atentam para a execução supervisionada de atividades de prevenção de doenças e promoção da saúde, por meio de ações domiciliares ou comunitárias, individuais ou coletivas, desenvolvidas de acordo com as diretrizes do Sistema Único de Saúde (SUS). Tais ações configuram-se por meio de instrumentos para diagnóstico demográfico e sociocultural da comunidade, da promoção de ações de educação para a saúde individual e coletiva, do registro (para fins exclusivos de controle e planejamento) das ações de saúde, nascimentos, óbitos, doenças e outros agravos à saúde, do estímulo à participação da comunidade nas políticas públicas voltadas para a área da saúde, da realização de visitas domiciliares periódicas para monitoramento de situações de risco à família e da participação em ações que fortaleçam os elos entre o setor saúde e outras políticas que promovam a qualidade de vida ${ }^{2}$.

A constituição de cada sujeito trabalhador, composta por perspectivas e idealizações, ao se chocar com um processo de trabalho que ignora tal subjetividade exerce uma ação específica capaz de produzir sofrimento, fazendo com que os coletivos criem estratégias conjuntas para superar o sofrimento correlato à realização do trabalho ${ }^{3,4}$.

Para o presente estudo é significativa a compreensão de que os ACSs são trabalhadores da saúde, com diretrizes de trabalho preestabelecidas legalmente e suscetíveis ao processo saúde-doença oriundo do trabalho. Dessa forma, a psicodinâmica do trabalho busca o entendimento desse processo, bem como alternativas de intervenção. Trata-se de ações transformadoras, que visam a apropriação da dimensão humana do trabalho por meio de uma perspectiva diferenciada, na qual podemos entender o desfecho das trajetórias de cada indivíduo trabalhador ${ }^{5}$.

Os sujeitos são singulares e apresentam demandas subjetivas antes mesmo de entrarem no mundo do trabalho, não as abandonando no momento de seu ingresso ${ }^{6}$. Pode-se dizer, portanto, que a personalidade dos indivíduos não pode ser totalmente integrada ao trabalho, pois está interligada simultaneamente a diferentes grupos (família, religião, entidades de classe, etc.). Tais grupos certamente se constituem em fontes de subjetividade em detrimento do trabalho, sendo que este possui caráter mecanicista e econômico, dificultando ao homem externar sua totalidade como pessoa ${ }^{7}$.

Este estudo pretende, portanto, analisar as 
perspectivas de mudanças no processo de trabalho do grupo de entrevistados a fim de proporcionar reflexões sobre a prática cotidiana do trabalhador ACS.

\section{MÉTODO}

Este estudo foi desenvolvido na cidade de Campo Bom, município brasileiro no estado do Rio Grande do Sul, pertencente à Região Metropolitana de Porto Alegre e ao chamado Vale do Rio dos Sinos. A cidade possui $60 \mathrm{~km}^{2}$ de área, 63767 habitantes e 98,13\% de cobertura da ESF. As unidades de ESF são Aurora, 25 de Julho, Imigrante, Operária, Quatro Colônias, Porto Blos, Rio Branco e Santa Lúcia.

Trata-se de um estudo do tipo descritivo exploratório, transversal, de abordagem qualitativa. Os participantes foram os trabalhadores Agentes Comunitários de Saúde que exerciam suas atividades nas Unidades de Estratégia Saúde da Família, com exceção dos trabalhadores em férias ou afastados do trabalho no período da coleta dos dados.

O estudo foi organizado dentro do Programa de Educação Permanente (PEP) e faz parte de um projeto "maior" que engloba análises qualiquantitativas, oriundo de uma parceria entre a Prefeitura e o Programa de Pós-Graduação em Saúde Coletiva da Universidade Federal do Rio Grande do Sul (PPGCOL-UFRGS), com aprovação sob o número 1.541 .369 no Comitê de Ética em Pesquisa (CEP) da instituição. Os trabalhadores receberam esclarecimentos quanto aos objetivos do estudo e sua condução e, nessa ocasião, todos se dispuseram a assinar o Termo de Consentimento Livre e Esclarecido, ou seja, não houve sujeitos que se negaram a participar.

Inicialmente os participantes responderam a um questionário sobre dados sociodemográficos e socioeconômicos. Posteriormente foram entrevistados a partir de um roteiro de questões norteadoras aplicadas de forma individual, respeitando a disponibilidade e a singularidade dos participantes. Essa entrevista buscou a compreensão dos aspectos que os profissionais gostariam de modificar no seu processo de trabalho.

O tratamento dos dados foi feito por meio da construção do Discurso do Sujeito Coletivo (DSC), que é uma técnica de tabulação e organização de dados qualitativos desenvolvida no fim da década de 90 e que tem como fundamento a teoria da Representação Social ${ }^{8}$. O DSC é um discurso-síntese elaborado com partes de discursos de sentido semelhante, por meio de procedimentos sistemáticos e padronizados?

A construção de um DSC foi realizada em três fases distintas de sistematização das ideias. Inicialmente buscamos estabelecer as expressões-chave (ECs) por meio das transcrições literais de parte dos depoimentos (contínuos ou não), visando o resgate de sua essência. Posteriormente, configuramos a ideia central (IC), realizando a síntese do conteúdo do discurso explicitado pelos participantes. Por último, construímos o DSC somando os discursos na tentativa de aglutinar as ideias, considerando os posicionamentos individuais e as diferentes possibilidades de categorização necessárias para representar o pensamento desse grupo de indivíduos em relação ao seu processo de trabalho ${ }^{10}$.

\section{RESULTADOS E DISCUSSÃo}

Participaram desta pesquisa 62 Agentes Comunitários de Saúde, com idade entre 23 e 61 anos, sendo $58(93,5 \%)$ mulheres e $4(6,5 \%)$ homens. Quanto à escolaridade, 1 deles (1,6\%) tem o ensino fundamental incompleto, 3 deles $(4,8 \%)$ têm o ensino fundamental completo, 14 deles $(22,6 \%)$ indicam ensino médio incompleto, $34(54,8 \%)$ citam ensino médio completo, $9(14,5 \%)$ têm ensino superior incompleto e 1 deles $(1,6 \%)$ indica ensino superior completo. A maioria dos trabalhadores, mais especificamente 50 deles 
$(80,6 \%)$, era casado ou morava junto com um parceiro, sendo que 51 (82,3\%) residiam em domicílios próprios, 5 (8,1\%) em domicílios alugados e 6 (9,7\%) em domicílios cedidos. A renda familiar média era de $\mathrm{R} \$ 2.949,34$. Os dados demonstram similaridade com outros estudos que objetivaram traçar perfis desta população, com exceção da caracterização da renda familiar, que se mostrou relativamente mais alta ${ }^{11-13}$. O tempo médio do exercício do trabalho remunerado durante a vida foi de 15,5 anos e o tempo médio do exercício da função de ACS foi de 5 anos. O grupo totaliza 11.581 famílias cadastradas, com distribuição individual entre 130 e 280, correspondendo a uma média de 186 famílias por ACS.
Neste estudo, as entrevistas realizadas forneceram 4 ideias centrais e 4 discursos, que são a base do material de análise.

Passamos a discutir os Discursos dos Sujeitos Coletivos, objeto deste trabalho, a partir da questão disparadora "Você teria algo que gostaria de modificar no seu processo de trabalho? Por quê?”. Do total de entrevistados obtivemos 60 respostas, uma vez que 2 deles não quiseram responder a essa pergunta. A Tabela 1, a seguir, apresenta os dados quantitativos, a partir da síntese das ideias centrais e suas respectivas frequências de manifestações.

Tabela 1. Síntese das ideias centrais e respectiva frequência de manifestações para a questão: "Você teria algo que gostaria de modificar no seu processo de trabalho? Por quê?"

\begin{tabular}{clcc}
\hline & IDEIAS CENTRAIS & N & $\%$ \\
\hline A & Não modificaria nada no meu processo de trabalho & 16 & 26,6 \\
\hline B & Ter maior resolubilidade diante de situações problema & 12 & 20,0 \\
\hline C & Ter mais valorização e reconhecimento profissional & 13 & 21,6 \\
\hline D & Operacionalização do cotidiano de trabalho & 23 & 38,3 \\
\hline
\end{tabular}

Nota: A soma da frequência de ideias centrais extrapola o número de 60 respostas e a porcentagem de 100\%, porque um mesmo indivíduo poderia apresentar mais de uma ideia central. Fonte: elaborada pelo autor.

Os sujeitos que "não modificariam nada no seu processo de trabalho" (DSC da ideia central A) sustentaram essa ideia a partir de discursos como o descrito a seguir:

No momento meu trabalho está ótimo, não tenho nada para modificar no modo de trabalho. Na UBS [Unidade Básica de Saúde] em que trabalho nós nos entendemos. Alguns são mais radicais, mas nós temos uma equipe de enfermeira e técnicos muito boa, que colabora com nossos problemas, e um médico maravilhoso, que nos escuta e nos trata muito bem. Penso que devemos tentar sempre nos adaptar à realidade em que vivemos, portanto acho que as coisas funcionam. Atualmente nossa unidade está completa e apoia nosso trabalho diariamente, diferente de antes, hoje todos somos um. Gosto muito da equipe que eu tenho, são atenciosos e cuidadores tanto comigo como com os usuários. Nós temos as reuniões semanalmente e ali colocamos para todos. Se é preciso mudar algo, em conjunto nós o fazemos. Acho que aos poucos está sendo modificado e para melhor. (DSC, maio de 2016, entrevista com autor). 
O discurso do sujeito coletivo dessa ideia central reafirma a necessidade que o trabalhador tem de ser escutado, algo já descrito por pesquisas anteriormente $^{14}$. A equipe completa e o estabelecimento de uma boa relação com ela, sobretudo com profissionais da saúde, também merece destaque. Enfatiza-se também a importância da reunião de equipe semanal para o fortalecimento de vínculos significativos, para o compartilhamento de situações cotidianas e para haver um espaço para construções coletivas ${ }^{15,16}$. O conceito de resiliência também pode ser observado, caracterizando-se como um fenômeno capaz de produzir resultados positivos de adaptação diante de experiências negativas ${ }^{17}$. "O estresse ocupacional ocorre quando há percepção do trabalhador da sua inabilidade para atender as demandas solicitadas pelo trabalho, causando sofrimento, mal-estar e um sentimento de incapacidade para enfrentá-las"18(p.18).

A ideia central que fala sobre "ter maior resolubilidade diante dos problemas do dia a dia" (DSC da ideia central B) foi expressa pela formulação do discurso a seguir:

Maior resolução dos casos e ou problemas das famílias. Se todos pudessem trabalhar juntos e em unidade seria muito melhor a resolução dos problemas do dia a dia; as vezes ficamos sozinha. Eu gostaria de poder ajudar mais as pessoas, principalmente aquelas pessoas idosas que não têm parentes. Gostaria de poder fazer mais, mas às vezes, em situações, não está ao nosso alcance. Queria que as pessoas tivessem algo para escutar elas, pois não têm. Gostaria que o SUS tivesse mais médicos disponíveis, remédios, especialistas sem filas, qualidade nos hospitais e postos de saúdes e mais promoção de saúde; isso faria com que nosso trabalho fosse melhor, pois conseguiríamos ajudar mais as pessoas. Ter soluções que fornecessem e melhorassem a vida de muitas famílias que passam por problemas tanto financeiramente como falta de alimentação, psicológicos; situações essas que interferem no convívio familiar, na relação com filhos, esposa(o) e até mesmo no trabalho. A base do nosso trabalho é orientar sobre vários assuntos, porém acredito que vai além disso, devido a entrarmos dentro da casa das pessoas e podermos acompanhar o drama de cada família e, muitas vezes, de mãos atadas, sem muito a ajudar. Mas apesar das dificuldades tentamos fazer o melhor e se as pessoas tivessem mais boa vontade e menos barreiras em relação ao problema dos outros. Gostaria de chegar nas residências e poder ter a liberdade de ajudar a pessoa com mais atendimentos, para assim ter aquela certeza de que seu trabalho foi muito grato. (DSC, maio 2016, entrevista com autor).

Na constituição deste discurso é possível observar que o desejo de poder resolver os problemas da população está presente e é a partir dele que outros nós críticos do sistema se evidenciam ${ }^{19}$. A carência de profissionais (médicos e especialistas), a falta de medicamentos, as filas e, por fim, a qualidade dos serviços e as políticas de promoção da saúde insuficientes são algumas situações relatadas ${ }^{20}$. O que o discurso evidencia, na verdade, está inteiramente ligado a um déficit na rede de atenção à saúde. Fica claro, portanto, que essa ideia central aponta falhas na política de saúde, que proporcionam entraves no processo de trabalho dos ACSs que, em várias situações, acabam sendo a "ouvidoria" do sistema para os usuários ${ }^{13,21}$.

Os trabalhadores relatam, também, a necessidade de maior valorização e reconhecimento profissional. O reconhecimento do profissional traz benefícios para os trabalhadores e seus empregadores. Os estímulos auxiliam para que os resultados esperados superem as expectativas. Por outro lado, a ausência deste reconhecimento, pode gerar impactos na saúde do trabalhador e, por conta disso, na saúde da comunidade ${ }^{22}$.

O discurso a seguir descrito representa o DSC da ideia central C, que fala sobre "ter mais valorização e reconhecimento profissional”.

Ser mais respeitado. Os usuários fossem mais participativos, para ver o que fazemos, como fazemos e para que fazemos, para isso a prefeitura fizesse uma ação com as famílias para entender nosso trabalho, assim aquelas famílias que não querem me receber, não sejam obrigadas a fazer cadastro. Não conseguimos atender a tudo e a todos e acho que isso acaba nos prejudicando 
muitas vezes. Somos mal interpretados e muitas das vezes não querem nos receber em suas residências; se mostrassem (dirigentes) a função real dos ACSs, marcações de consultas para urgências, por exemplo. O município poderia dar mais valor ao trabalho do agente comunitário, pois em muitos casos não temos voz, onde quem "bate" com a coordenação, acaba sendo visado. O município recebe do PMAQ [Programa Nacional de Melhoria do Acesso e da Qualidade da Atenção Básica], e não repassa para os ACSs, não temos, guarda-pó, pasta e outros materiais; a justificativa é que está sempre em licitação. Precisamos de escuta e respeito dos superiores para com os agentes comunitários. Queria ser tratado com o devido respeito pela função que ocupamos e que levassem a sério os problemas de nossos usuários. Que toda a equipe trabalhasse em harmonia e que nosso trabalho fosse reconhecido, sendo mais valorizada e respeitada por os demais profissionais, pois eles dependem mais do trabalho dos ACSs do que nós mesmos. Tivéssemos o curso técnico de agente comunitário de saúde, mais estímulos e um melhor o salário. Mais recursos e reconhecimento, porque, com melhores condições para exercer teu trabalho, tu consegue atender melhor e um maior número de usuários, se teu trabalho é valorizado, tu trabalha motivado a fazer cada vez melhor. Ter poder de tentar fazer elas (famílias) verem que a vida não tem só lado ruim, tem muita coisa boa. Se minha profissão fosse mais reconhecida (financeiramente) pela gestão e tivéssemos também o reconhecimento de voz, acho que trabalharíamos com mais satisfação. (DSC, maio 2016, entrevista com autor).

O discurso descrito anteriormente pode ser analisado a partir de duas interfaces e corrobora com diversos levantamentos científicos. Uma dessas interfaces corresponde à visão do usuário em relação ao trabalho do ACS e a outra está relacionada ao reconhecimento profissional da gestão para com o trabalhador. Inicialmente são apontadas diversas barreiras no processo de cuidado a partir da fragilidade do reconhecimento de funções e da importância do trabalho, que provoca uma não participação dos usuários, resistência na realização do cadastramento e hostilidade para com os trabalhadores ${ }^{22}$. Posteriormente o discurso aponta para a necessidade de valorização, respeito, escuta, união, materiais adequados, condições de trabalho, formação técnica e incentivos salariais, como determinantes na motivação para o trabalho ${ }^{15,23}$. Também foi observado que a valorização e o reconhecimento podem se manifestar de distintas maneiras: clareza nas suas atribuições, educação permanente do trabalhador, integração da equipe, ou mesmo, um simples "obrigado" dito por todos os atores do processo de trabalho (usuários, equipe e gestão) $^{15}$.

A necessidade de modificações na "operacionalização do cotidiano do processo de trabalho" compõe o DSC da ideia central D, que pode ser expressada pelo discurso narrado na sequência.

Sempre temos algo de novo a aprender e pôr em prática. Sempre tem coisas que podemos melhorar, para isso temos que ter uma ideia de todos da equipe, para ver se esta é a melhor modificação no nosso trabalho. Aprender com diversos tipos de opiniões e saber respeitar cada uma delas, principalmente quando estamos trabalhando com uma equipe de profissional, ou com a própria população. Acho que ficamos muito tempo envolvidos com preenchimento de papéis, muito tempo dentro da unidade digitando produtividade, essa parte me deixa muito nervosa. Que fosse cedido um horário especial para as pessoas que moram bem distantes do posto, poderem agendar consulta, já que há grande dificuldade. Que a equipe tivesse a mesma visão de situação de vida que os usuários vivem. "Não julgar", e sim ter mais acolhimento e conhecer mais a integridade do usuário. Falta muita visita domiciliar dos enfermeiros e médicos; tem muita resistência. Os problemas do sistema e não diretamente no meu trabalho, a questão da distância da minha área e, talvez, algumas mudanças em mim mesma para fazer melhor. Se pudesse humanizar mais os profissionais - fazer com que eles se colocassem no lugar e nas dores das pessoas, modificar mais, pois modificou um pouco, a visão da equipe do posto sobre o usuário. Eu vejo a situação total deles e, a outra parte, vê o usuário só no posto; gostaria que os colegas de dentro da unidade conseguissem ver a realidade das pessoas. Ter um apoio maior na UBS com outros profissionais sobre usuários, com menos famílias para visitar, pois a demanda está muita, mas quando tiver outra área vai melhorar. A forma de registrar as visitas domiciliares, bem como o resultado delas, está muito desfocado do 
usuário (usa-se, agora, somente número do SUS), no final tenho que fazer registro "paralelo" para identificar o usuário. Registrando, por escrito e extenso gravava, atualmente está "distante" da realidade. Dificuldade de lembrar das situações vivenciadas junto com usuários; está muito no automático (apertar um botão e pronto). Temos microáreas muito grandes, com muitos usuários; a médica e nós, agentes, não vencemos visitar e atender bem a todos; a unidade fica muito sobrecarregada. Gostaria que viesse logo dois médicos que faltam para que podermos melhorar ainda mais, nosso trabalho. Não ver mais essas filas em frente ao posto todos os dias, antes do amanhecer. Também a falta de respeito de alguns usuários com os outros e também com a equipe. Gostaria que as equipes conseguissem ser mais unidas, isso beneficiaria não só a nós, mas aos usuários. Gostaria de receber materiais com mais qualidade, como caneta que funciona bem, lápis que aguente ser apontado, sacola. Ajuda a motivar o trabalhador melhorar os materiais de trabalho, ter o trabalho reconhecido. Gostaria que muitas coisas que são tão belas na teoria funcionassem também na prática. (DSC, maio 2016, entrevista com autor).

A última ideia central levantada por este estudo fala sobre o dia a dia dos ACSs. O discurso sistematiza insatisfações quanto ao processo de trabalho propriamente dito e suas nuances. É apresentada uma argumentação que dá um caráter de corresponsabilidade para os diferentes atores envolvidos, estabelecendo a necessidade de se ter flexibilidade para aprender coisas novas. Percebese um incômodo com os processos burocráticos do trabalho, principalmente aos registros e à produtividade que, segundo o discurso, se mostram distantes e perderam a singularidade, transformando o usuário em um número, fato que pode estar relacionado ao excesso de famílias cadastradas que, em alguns casos, gera a sensação de mecanicidade no trabalho ${ }^{24-26}$. A relação entre a equipe e os usuários também merece atenção, uma vez que o discurso aponta para um distanciamento não apenas geográfico, mas ideológico, social, humano, cultural e empático ${ }^{27}$.

\section{CONCLUSÕES}

A maioria dos trabalhadores, representada por 44 deles $(73,33 \%)$, relata que teria algo a ser modificado no seu processo de trabalho, enquanto que 16 deles (26,66\%) relatam que não mudariam nada. Verificou-se que a ideia mais compartilhada entre os entrevistados foi a que aponta alguns problemas no cotidiano de trabalho, validada pela ideia central D, destacada por $38,3 \%$ dos entrevistados. Dentre os aspectos a serem modificados e/ou melhorados estão: burocratização do trabalho, reorganização das marcações de consulta, respeito, união das equipes, maior participação dos profissionais de saúde (médicos e enfermeiros) nas visitas domiciliares, equipes incompletas, automatização do processo de trabalho, grande número de famílias cadastradas, reconhecimento, ausência e/ou sucateamento de materiais básicos de trabalho.

Esperamos que este estudo possa oferecer um panorama da atual situação do processo de trabalho dos ACSs do município, bem como apontar para a necessidade de se estabelecerem espaços sistemáticos de escuta e acolhimento para esses profissionais. Sendo esse trabalhador um importante articulador das políticas públicas de saúde, os apontamentos aqui descritos devem ser utilizados no sentido de potencializar e melhorar suas condições de trabalho.

\section{REFERÊNCIAS}

1. Nunes MO, Trad LB, Almeida BA, Homem CR, Melo MCIC. O agente comunitário de saúde: construção da identidade desse personagem híbrido e polifônico. Cad Saude Publica [Internet]. 2002 [acesso em 20 ago 2019];18(6):1639-46. Disponível em: http://www. scielo.br/scielo.php?script=sci_arttext\&pid=S0102311X2002000600018\&lng=en

2. Lei n. 11.350 , de 5 de outubro de 2006. Regulamenta o $\S 5^{\circ}$ do art. 198 da Constituição, dispõe sobre o aproveitamento de pessoal amparado pelo parágrafo único do art. $2^{\circ}$ da Emenda Constitucional no 51, de 14 de fevereiro de 2006, 
e dá outras providências. Brasília: Diário Oficial da União [Internet]. 2006 [acesso em 22 jul 2015]. Disponível em: http://www.planalto.gov.br/ccivil_03/_ato2004-2006/2006/ lei/l11350.htm

3. Dejours C, Abdoucheli E, Jayet C. Psicodinâmica do trabalho: contribuição da escola dejouriana à análise da relação prazer, sofrimento e trabalho. São Paulo: Atlas; 1994.

4. Vasconcellos NPC, Costa-Val R. Avaliação da qualidade de vida dos agentes comunitários de saúde de Lagoa Santa - MG. Rev APS [Internet]. 2008 [acesso em 10 ago 2019];11(1):17-28. Disponível em: http://www.ufff.br/nates/ files/2009/12/017-028.pdf

5. Mendes R, Dias, EC. Da medicina do trabalho à saúde do trabalhador. Rev Saude Publica [Internet]. 1991 [acesso em 5 set 2019];25(5):341-9. Disponível em: https://www.nescon. medicina.ufmg.br/biblioteca/imagem/2977.pdf

6. Tannenbaum AS. Psicologia social das organizações do trabalho. São Paulo: Atlas; 1976.

7. Aquino CP. Administração de recursos humanos: uma introdução. São Paulo: Atlas; 1979.

8. Lefevre F, Lefevre AMC. O discurso do sujeito coletivo: um novo enfoque em pesquisa qualitativa. Caxias do Sul: Editora da Universidade de Caxias do Sul; 2003.

9. Lefevre F, Lefevre AMC. Pesquisa qualitativa levada a sério. 2003 [acesso em 21 jun 2015]. In: Faculdade de Saúde Pública da Universidade de São Paulo [Internet]. Disponível em: http://www.fsp.usp.br/ flefevre/Discurso_o_que_e.htm

10. Lefèvre AMC, Lefèvre F, Cardoso MRL, Mazza MMPR. Assistência pública à saúde no Brasil: estudo de seis ancoragens. Saude Soc [Internet]. 2002 [acesso em 02 jan 2018];11(2):35-47. Disponível em: http://www. scielo.br/scielo.php?script=sci_arttext\&pid=S0104$12902002000200004 \& \operatorname{lng}=\mathrm{en}$

11. Lino MM, Lanzoni GMM, Albuquerque GL, Schveitzer MC. Perfil socioeconômico, demográfico e de trabalho dos agentes comunitários de saúde. Cogitare Enferm [Internet]. 2012 [acesso em 10 jan 2019];17(1):57-64. Disponível em: https://revistas.ufpr.br/cogitare/article/view/26375/17568

12. Santos KT, Saliba NA, Moimaz SAS, Arcieri RM, Carvalho ML. Agentes comunitários de saúde: perfil adequado à realidade do programa de saúde da família?
Cien Saude Colet [Internet]. 2011 [acesso em 1 jun 2016];16:1023-8. Disponível em: http://www.scielo.br/pdf/ csc/v16s1/a35v16s1.pdf

13. Silva ATC, Menezes PR. Esgotamento profissional e transtornos mentais comuns em agentes comunitários de saúde. Rev Saude Publica [Internet]. 2008 [acesso em 1 jun 2016];42(5):921-9. Disponível em: http://www.scielo.br/pdf/ rsp/v42n5/6933.pdf

14. Souza LJR, Freitas MSC. O agente comunitário de saúde: violência e sofrimento no trabalho a céu aberto. Rev Baiana Saude Publica [Internet]. 2011 [acesso em 1 jun 2016];35(1):96-109. Disponível em: http://files.bvs.br/ upload/S/0100-0233/2011/v35n1/a2100.pdf

15. Costa EM, Ferreira DLA. Percepções e motivações de agentes comunitários de saúde sobre processo de trabalho em Teresina, Piauí. Trab Educ Saude [Internet]. 2012 [acesso em 15 set 2019];9(3):461-78. Disponível em: http:// www.scielo.br/pdf/tes/v9n3/v9n3a07.pdf

16. Lopes DMQ, Beck CLC, Prestes FC, Weiller TH, Colomé JS, Silva GM. Agentes comunitários de saúde e as vivências de prazer-sofrimento no trabalho: estudo qualitativo. Rev Esc Enferm USP [Internet]. 2012 [acesso em 10 ago 2019];46(3):633-40. Disponível em: http://www. scielo.br/pdf/reeusp/v46n3/15.pdf

17. Masten Ann S. Ordinary magic: resilience processes in development. Am Psychol [Internet]. 2001 [acesso em 01 ago 2019];56(3):227-38. Disponível em: https://www.ncbi. nlm.nih.gov/pubmed/11315249

18. Souza AD, Campos CS, Silva EC, Souza JO. Estresse e o trabalho [monografia]. Campo Grande (MS): Sociedade Universitária Estácio de Sá; 2002.

19. Brand C, Antunes R, Fontana R. Satisfações e insatisfações no trabalho do agente comunitário de saúde. Cogitare Enferm [Internet]. 2010 [acesso em 01 ago 2019];15(1):40-7. Disponível em: https://revistas.ufpr.br/ cogitare/article/view/17143/11285

20. Bezerra AFB, Espirito Santo ACG, Batista Filho M. Concepções e práticas do agente comunitário na atenção à saúde do idoso. Rev Saude Publica [Internet]. 2005 [acesso em 5 dez 2018];39(5):809-15. Disponível em: http://www. scielo.br/pdf/rsp/v39n5/26303.pdf

21. Gama PF. Quem acolhe o agente de saúde? O agente comunitário de saúde como mediador de conflitos na 
estratégia de saúde da família. Rev Habitus [Internet]. 2013 [acesso em 05 dez 2018];11(2):47-66. Disponível em: https:// revistas.ufrj.br/index.php/habitus/article/view/11416/8366

22. Oliveira AR, Chaves AEP, Nogueira JA, Sá LD, Collet N. Satisfação e limitação no cotidiano de trabalho do agente comunitário de saúde. Rev Eletron Enferm [Internet]. 2010 [acesso em 5 dez 2018];12(1):28-36. Disponível em: https:/ www.fen.ufg.br/revista/v12/n1/pdf/v12n1a04.pdf

23. Wei MFP, Carvalho AMP. O trabalho do agente comunitário de saúde: fatores de sobrecarga e estratégias de enfrentamento. Rev Enferm UERJ [Internet]. 2009 [acesso em 05 dez 2018];17(4):563-8. Disponível em: https:// www.facenf.uerj.brv17n4/v17n4a19.pdf

24. Teixeira CF, Solla JP. Modelo de atenção à saúde: vigilância e saúde da família [Internet]. Salvador: Editora da Universidade Federal da Bahia, 2006 [acesso em 05 abr 2016]. Disponível em: http://static.scielo.org/scielobooks/f7/ pdf/teixeira-9788523209209.pdf

25. Wai MFP. O trabalho do agente comunitário de saúde na Estratégia Saúde da Família: fatores de sobrecarga e mecanismos de enfrentamento em Ribeirão Preto/SP [dissertação]. Ribeirão Preto (SP): Escola de Enfermagem da Universidade de São Paulo; 2007.

26. Simões AR. O agente comunitário de saúde na equipe de saúde da família: fatores de sobrecarga de trabalho e estresse. Rev Saude Publica [Internet]. 2009 [acesso em 10 jul 2018];2(1):6-21. Disponível em: http://revista.saude. sc.gov.br/index.php/inicio/article/view/37/61

27. Ilha S, Dias MV, Backes DS, Backes MS. Vínculo profissional-usuário em uma equipe da estratégia de saúde da família. Cienc Cuid Saude [Internet]. 2014 [acesso em 01 jan 2019];13(3):556-62. Disponível em: http://periodicos. uem.br/ojs/index.php/CiencCuidSaude/article/view/19661/ pdf_229 